\title{
Phyotochemical Properties of Acalypha indica (L), and its Antimicrobial Potential against Human Pathogens
}

\author{
V. Thamil Priya ${ }^{1 *}$ (D) N. Balasubramanian ${ }^{2} \mathbb{D}$, V. Shanmugaiah ${ }^{3}$ iD and C. Karunakaran ${ }^{1 *}$ \\ ${ }^{1}$ Department of Chemistry, VHNSN College, Viruthunagar - 626001 , Tamil Nadu, India. ${ }^{2}$ Department of Immunology, \\ ${ }^{3}$ Department of Microbial Technology, School of Biological Sciences, Madurai Kamaraj University, Madurai - 625021, \\ Tamil Nadu, India.
}

\begin{abstract}
The present work has been investigated for important medicinal properties of Acalypha indica (L). $A$. indica crude extract was obtained, significant phytochemicals and antibacterial activity substance for the control of numerous antibiotic resistance bacteria such as Escherichia coli, Salmonella typhi, Staphylococcus epidermidis, Bacillus cereus, Staphylococcus marcescens, Staphylococcus aureus, Streptococcus agalactiae, Streptococcus pyogenes and Streptococcus dysgalactiae. Antibacterial activity of $A$. indica was performed using the crude extract on Muller- Hinton agar with and without $5 \%$ sheep blood by the well diffusion method. We found Ethanol is the most favorable solvent for maximum amount of $A$. indica extract followed by Acetone, however acetone has more antimicrobial activity. Furthermore, we found Benzene and Diethyl ether are low yielding solvent for $A$. indica extract. $A$. indica extract on antimicrobial activity showed remarkable activity in S. typhi, B. cereus followed by $S$. epidermidis. Eight, phytochemicals tested in A. indica extract showed the existence of tannin, saponin, alkaloid, flavonoid and phenol. Petroleum ether and ethyl acetate solvent (4.2:0.8), was most optimum for the separation of more compounds by TLC analysis. In A. indica four major spots were detected, of these, two major spots were scrabbled from the TLC plates and checked for antimicrobial activity against $B$. cereus pathogen. $B$. cereus was selected based on our preliminary results, which showed significant activity among other pathogens.
\end{abstract}

Keywords: A. indica, antimicrobial activity, crude extract, human pathogens, phytochemicals

*Correspondence: bthamilpriya@gmail.com; ckarunakaran2000@gmail.com

(Received: February 13, 2020; accepted: March 21, 2020)

Citation: V. Thamil Priya, N. Balasubramanian, V. Shanmugaiah and C. Karunakaran, Phyotochemical Properties of Acalypha indica (L), and its Antimicrobial Potential against Human Pathogens, J. Pure Appl. Microbiol., 2020; 14(1): 319-326. https://doi. org/10.22207/JPAM.14.1.33

(C) The Author(s) 2020. Open Access. This article is distributed under the terms of the Creative Commons Attribution 4.0 International License which permits unrestricted use, sharing, distribution, and reproduction in any medium, provided you give appropriate credit to the original author(s) and the source, provide a link to the Creative Commons license, and indicate if changes were made. 


\section{INTRODUCTION}

Medicinal plants have been used for the treatment of human diseases and also used for prophylactic purposes (Nostro et al., 2000). An increasing interest in the herbal based treatment for disease control observed in different countries and herbal remedies integrated into orthodox herbal practice (Wachtel-Galor and Benzieet, 2011). Some of the diseases such as malaria, epilepsy, infantile convulsion, diarrhea, dysentery, fungal and bacterial infections have been treated using medicinal plants (Sofowora, 1996). Medicinal plants are considered as a chemical factory, since it contains alkaloids, glycosides, saponins, resins, oleoresins, sesquiterpene, lactones and oils (Singh, 2005).

Acalypha indica (L) family of Euphorbiaceae, its annual herb and commonly found in gardens, roadsides, waste places, fields throughout the plains of India and commonly known as "Kuppaimeni (Burkill, 1985). In addition, it is found in many parts of Asia, including India, Pakistan, Sri Lanka and throughout Tropical Africa and South America (Davy et al., 2012). A. indica used as emetic, expectorant, laxative, diuretic bronchitis, pneumonia, asthma and pulmonary tuberculosis. In homeopathy, this plant is used for severe cough, bleeding from lungs, haemopytosis and incipient phthisis (Devi et al., 2012).

Synthetic drugs may have side effects and antibiotic resistant microorganisms also increasing every year. Hence, researchers are paying more attention in herbal drug discovery for the treatments of varies diseases (Esakkirajan et al., 2014). The traditional medicinal plantsbased treatment covers the basic health needs in the developing countries (Alavijeh et al., 2012). India is one of the richest and different cultural traditions connected with the use of medicinal plants to cure different diseases. Hence, in this present study, we have taken $A$. indica, medicinal plants, to check antimicrobial activity against human disease causing bacteria pathogens and to evaluate phytochemical properties to understand the therapeutic value of this important plant.

\section{MATERIALS AND METHODS Plants collection}

Healthy, fresh leaves of $A$. indica were collected in and around the campus of Madurai
Kamaraj University, Madurai, Tamil Nadu, India. Collected leaves were washed thoroughly with tap water and then distilled water. The leaves were dried under the shade and grinded into fine powder using an electric grinder.

\section{A. indica extract preparation}

$A$. indica extract was prepared from the dried fine powder, using organic solvents. Five solvents (Polar nature- Ethanol, Acetone, non-polar nature -Benzene, Ethyl acetate, Diethyl ether), were used to extract compounds (Molychem, India). One-gram of powder was added in a 250 $\mathrm{ml}$ Erlenmeyer flask with the above said solvents $(1: 10, w / v)$ and kept at room temperature for 3 days with frequent mixing. The samples were filtered (Whatman No 3), the extract collected, and solvents were evaporated at room temperature until dry. This process was repeated for three times and dried extracts were dissolved in Dimethyl sulphoxide (DMSO).

Growth and maintenance of bacterial culture Pathogens such as E. coli, S. typhi, S. marcescens, K. pneumoniae, B. cereus, $S$. epidermidis, $S$. aureus were grown LB Agar or LB Broth (Himedia, India), whereas S. agalactiae, S. pyogenes and $S$. dysgalactiae were obtained from Microbial Technology and Immunology Department respectively, Madurai Kamaraj University, Madurai, Tamil Nadu, India and grown on blood agar or Todd-Hewitt broth with $1 \%$ yeast extract. Mueller-Hinton agar with and without sheep blood $(5 \%)$ was used for antimicrobial activity assay. The cultures were grown at $37^{\circ} \mathrm{C}$ for 20-24 hrs. All the media were prepared according to manufacturer's instructions (Himedia, India).

\section{Antimicrobial activity assay}

Antimicrobial activity with crude extracts was performed using the well diffusion method on Muller-Hinton agar with and without $5 \%$ sheep blood (Gupta et al., 2013). Fresh colonies of $E$. coli, S. typhi, S. marcescens, K. pneumoniae, B. cereus, $S$. epidermidis, $S$. aureus were grown one $\mathrm{ml}$ of sterilized LB Broth, while S. agalactiae, $S$. pyogenes and $S$. dysgalactiae were grown on ToddHewittt broth with $1 \%$ yeast extract and incubated at $37^{\circ} \mathrm{C}$ for $18-20 \mathrm{hrs}$. A sterile cotton swab was dipped into the culture and was spread uniformly on respective Mueller-Hinton agar plates with and without sheep blood (5\%). Crude extract in DMSO at 1, 5, 10 and $15 \mathrm{mg}$ in an each well was added. 
Tetracycline $(50 \mu \mathrm{g}$ each well) and DMSO were used as positive and negative control respectively for all the experiments. Inoculated plates were incubated at $37^{\circ} \mathrm{C}$ for $20-24 \mathrm{hrs}$. Subsequently, a zone of inhibition was measured by a standard ruler scale (Himedia, India).

\section{Phytochemical analysis}

Phytochemical analysis in ethanolic extract was performed by standard procedure described by Sofowora (1990), Trease and Evans (1989) and Harborne (1973).

\section{Tannin assay}

A $2 \mathrm{ml} \mathrm{A}$. indica extract was mixed with $2 \mathrm{ml}$ distilled water, then a few drops of Ferric Chloride $\left(\mathrm{FeCl}_{3}\right)$ solution were added and color formation was observed.

\section{Saponin assay}

A $2 \mathrm{ml}$ plant extract was taken in a test tube and shaken vigorously with $5 \mathrm{ml}$ distilled water, warmed in a water bath and then foam formation was observed.

\section{Alkaloid assay}

A $3 \mathrm{ml}$ plant extract was mixed with $3 \mathrm{ml}$ $\mathrm{HCl}(2 \%)$ on the steam bath. From the mixture each one $\mathrm{ml}$ was added in two test tubes. Few drops of Dragendorff's reagent were added in one tube and Mayer's reagent was added in another tube then color formation was observed.

\section{Flavonoid assay}

A $1 \mathrm{ml}$ extract with $1 \mathrm{ml}$ of $10 \%$ lead acetate solution was added and color formation was observed.

Terpenoid assay

A $2 \mathrm{ml}$ extract was mixed with $2 \mathrm{ml}$ of $\mathrm{CHCl}_{3}$ then evaporated to dry. After that $2 \mathrm{ml}$ of concentrated $\mathrm{H}_{2} \mathrm{SO}_{4}$ was added and heated for 2 minutes and then color formation was observed.

\section{Glycoside assay}

A $2 \mathrm{ml}$ extract with diluted $\mathrm{HCl}$ was added then $2 \mathrm{ml}$ of Sodium Nitropruside in Pyridine followed by Sodium hydroxide solution was added and color formation was observed.

\section{Steroid assay \\ Salkowski's test}

A $2 \mathrm{ml}$ plant extract was mixed with $2 \mathrm{ml}$ chloroform then $2 \mathrm{ml}$ concentrated sulphuric acid was added then color formation was recorded.

\section{Liebermann Burchard test}

A $2 \mathrm{ml}$ plant extract was mixed with $2 \mathrm{ml}$ chloroform then added concentrated sulphuric acid and acetic acid, the development of color formation was observed.

\section{Phenol assay}

Ethanol extract $(500 \mathrm{mg}$ ) was dissolved in $5 \mathrm{ml}$ distilled water. Few drops of neutral $5 \%$ ferric chloride solution were added. A dark green color indicated the presence of phenolic compounds.

\section{Thin Layer Chromatography (TLC) analysis}

TLC analysis of the crude compound was performed in pre-coated silica gel plates (E-Merck, Germany) to detect, the presence of phytochemicals in A. indica. The crude extract was spotted with capillary tube and solvent front was allowed to run for $80 \%$ of the plate. The crude was eluted with Petroleum ether and Ethyl acetate with the ratio 4.2:0.8. Spots with $R_{f}$ values were identified under UV Light (254 nm) absorbance.

Antimicrobial activity using partially purified compounds

The two major spots in the TLC plates were scrabbled and checked antimicrobial activity against selected pathogen of $B$. cereus. Briefly, an each spot was collected and dissolved in ethanol, further centrifuged at 10,000 rpm for $15 \mathrm{~min}$. The supernatant was collected air dried until ethanol evaporation after that it was dissolved in $200 \mu \mathrm{l}$ DMSO. Antimicrobial activity was performed using the well diffusion method on Muller-Hinton agar (Gupta et al., 2013). Fresh colonies of B. cereus, were grown in $1 \mathrm{ml}$ sterilized LB broth, incubated at $37^{\circ} \mathrm{C}$ for $18-20 \mathrm{hrs}$. A sterile cotton swab was dipped into the culture and was spread uniformly on Mueller-Hinton agar plates. A $9 \mathrm{~mm}$ well was prepared and $100 \mu$ l of sample (in DMSO), was added to each well. Tetracycline $(50 \mu \mathrm{g}$ each well) and DMSO were used as positive and negative control for all experiments. The plates were incubated at $37^{\circ} \mathrm{C}$ for $20-24$ hrs subsequently; zone of inhibition was measured by a standard ruler scale (Himedia, India).

Table 1. Effect of different solvent on $A$. indica crude extract

\begin{tabular}{lc}
\hline Solvent & $\begin{array}{c}\text { Net weight of } \\
\text { A. indica } / 5 \mathrm{gm}\end{array}$ \\
\hline Ethanol & 0.56 \\
Acetone & 0.26 \\
Benzene & 0.02 \\
Ethyl acetate & 0.23 \\
Diethyl ether & 0.08
\end{tabular}


Table 2. Antibacterial activity using $A$. indica extract with acetone against bacterial pathogens

\begin{tabular}{lccccc}
\hline $\begin{array}{l}\text { Name of the } \\
\text { Bacteria }\end{array}$ & $1 \mathrm{mg}$ & $5 \mathrm{mg}$ & $10 \mathrm{mg}$ & $15 \mathrm{mg}$ & Tetracycline \\
\hline K. pneumoniae & - & - & 9 & 11 & 31 \\
S. marcescens & - & - & 1 & 3 & 16 \\
S. typhi & - & 3 & 11 & 11 & 36 \\
E. coli & - & - & 9 & 10 & 16 \\
S. epidermidis & - & - & 3 & 11 & 36 \\
S. aureus & - & - & - & 3 & 31 \\
B. cereus & - & 3 & 5 & 6 & 19 \\
S. agalactiae & - & 1 & 4 & 6 & 21 \\
S. disgalactiae & - & 2 & 4 & 5 & 21 \\
S. pyogenes & - & - & 2 & 2 & 16 \\
\hline
\end{tabular}

Zone of inhibition in $\mathrm{mm}$ (without disc size, $9 \mathrm{~mm}$ )

Table 3. Antibacterial activity using $A$. indica extract with ethyl acetate against bacterial pathogens

\begin{tabular}{lccccc}
\hline $\begin{array}{l}\text { Name of the } \\
\text { Bacteria }\end{array}$ & $1 \mathrm{mg}$ & $5 \mathrm{mg}$ & $10 \mathrm{mg}$ & $15 \mathrm{mg}$ & Tetracycline \\
\hline K. pneumoniae & - & - & 9 & 13 & 36 \\
S. marcescens & - & - & 6 & 6 & 11 \\
S. typhi & - & - & 11 & 11 & 36 \\
E. coli & - & - & 3 & 4 & 10 \\
S. epidermidis & - & - & 9 & 11 & 36 \\
S. aureus & - & - & - & 3 & 31 \\
B. cereus & - & 2 & 5 & 5 & 23 \\
S. agalactiae & - & - & 4 & 6 & 11 \\
S. disgalactiae & - & - & 4 & 5 & 11 \\
S. pyogenes & - & - & 2 & 2 & 11 \\
\hline
\end{tabular}

Zone of inhibition in $\mathrm{mm}$ (without disc size, $9 \mathrm{~mm}$ )

\section{RESULTS AND DISCUSSION}

Preparation of plant extract

Medicinal plants with different organic solvents were used to extract the active compounds for various applications. In this present study, $A$. indica leaf extract was used for phytochemical analysis and antimicrobial activity. We used five different solvents including polar and nonpolar solvents to extract compounds. Among five solvents used, the maximum extract was obtained in ethanol $(0.56 \mathrm{~g})$ followed by acetone $(0.26 \mathrm{~g})$ (Table 1). Similarly, ethanol solvent is optimum for maximum extract in Dodonaea viscosa (Khurram et al., 2009), Boerhavia diffusa (Apu et al., 2012), Pavatta indica (Gupta et al., 2013) and Bambusa vulgaris (Lodhi et al., (2016). On the other hand, Ujwal et al., (2007) reported good extract yield in Pongamia pinnata using petroleum ether and ethyl acetate. In contrary, maximum extract yield in $P$. pinnata leaf, bark, flower, and the root with chloroform was reported (Satish et al., 2017). Rashid et al., (2014) demonstrated active compounds within beetle leaves extract with only boiling water. These reports suggested that each solvent system is suitable depends on the presence of phytochemical compounds.

\section{Antimicrobial activity}

A. indica crude extract was used to test the antibacterial activity against ten human pathogens which cause different diseases. Among five solvents were used to extract the compounds in $A$. indica acetone performs well followed by ethyl acetate have good antimicrobial activity compared to other three solvent. In this study, we have shown that Ethanol is optimum for more plant extract; however the antimicrobial activity is low 
Table 4. Phytochemical analysis in A. indica crude extract

\begin{tabular}{lc}
\hline Phytochemical & A. indica \\
\hline Tannins & + \\
Saponins & + \\
Alkaloids & + \\
flavonoids & + \\
Terpenoids & - \\
Glycosides & - \\
Steroids & - \\
Phenols & + \\
\hline
\end{tabular}

compared to acetone extract. Interesting to note that, each solvent extract inhibited the growth of bacteria, but the zone of inhibition is varied among bacterial pathogens. We used 1 to $15 \mathrm{mg}$ of crude extract to check antibacterial activity and acetone extract inhibited S. typhi $(3-11 \mathrm{~mm})$ followed by $B$. cereus (3-6 mm) (Table 2). Further, ethyl acetate extract gave maximum zone of inhibition was observed for K. pneumonia (9-13mm), S. typhi $(11 \mathrm{~mm})$ and S. epidermidis (9-11), (Table 3, Fig. 1). Similarly, The acetone extract of $A$. indica showed the maximum zone of inhibition against $S$. aureus and $B$. subtilis, minimum inhibition of $E$. coli and Klebsiella sp. (Rajaselvam et al., 2012), On the other hand, maximum inhibition was observed in S. auries with D. viscosa extract (Rani et al., 2009), further, S. aureus, S. pyogenes and K. pneumoniae were inhibited by $D$. viscosa extract (Ramamurthy et al., 2013). Shafeeq et al., (2018) demonstrated ethanolic leaf extracts of Cassia fisculata showed maximum inhibition in S. aureus, $S$. epidermidis

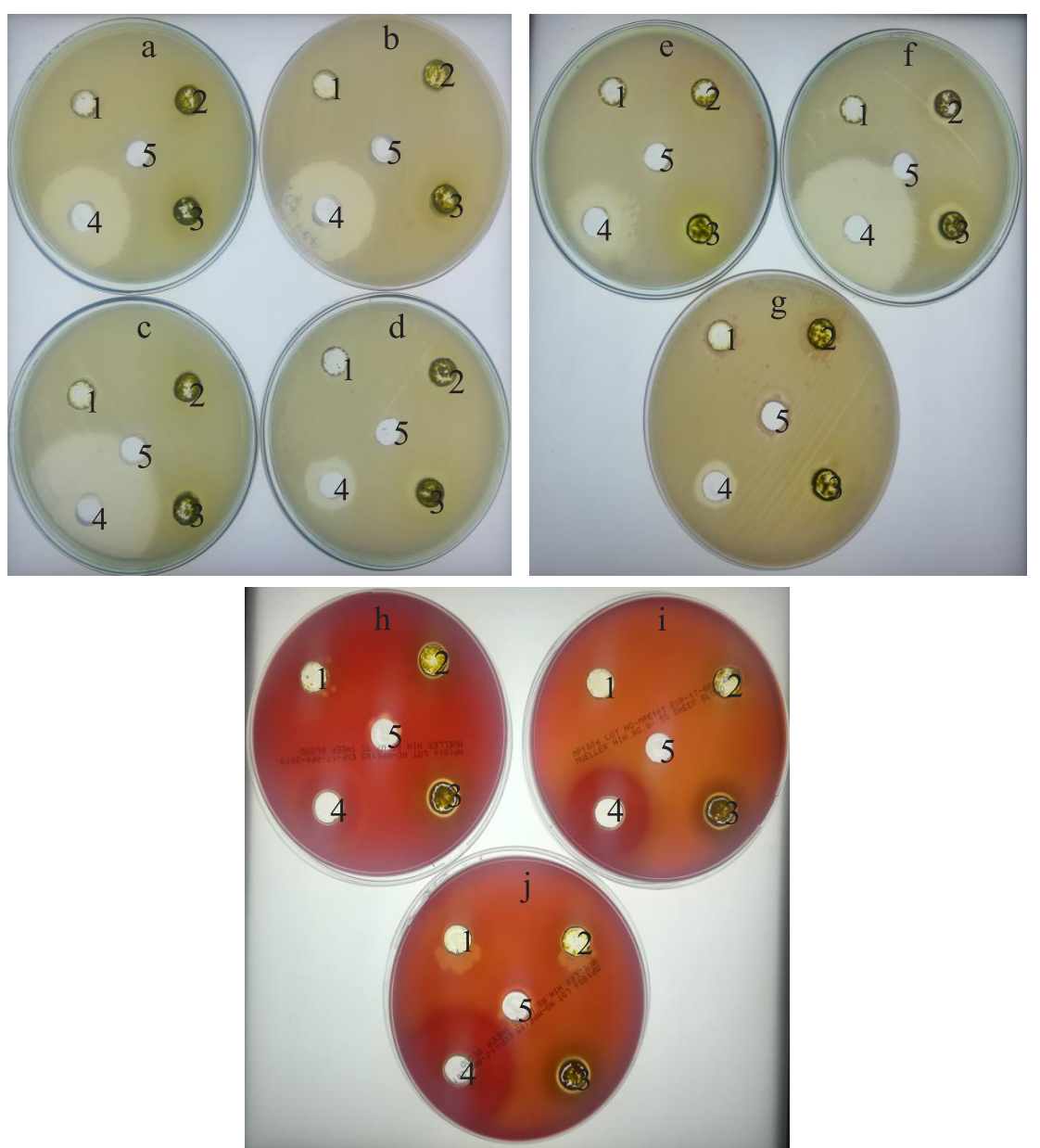

Fig. 1. Antibacterial activity using $A$. indica extract with acetone against bacterial pathogens a. K. pneumonia b. S. epidermidis, c. E. coli d. S. aureus, e. B. cereus, f. S. typhi, g. S. marcenses, h. S. agalactiae, i. S. dysgalactiae, j. S. pyogenes $1.1 \mathrm{mg}, 2.5 \mathrm{mg}, 3.10 \mathrm{mg}$, 4.Tetracycline, 5. Negative control (DMSO) 


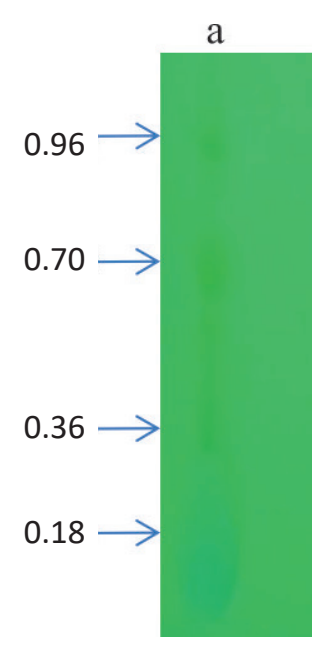

Fig. 2. TLC analysis in A. indica crude extract

and B. cereus. In addition, Satish et al., (2017) has shown in vivo study $P$. pinnata extract has, potent antimalarial activity was tested against Plasmodium berghei. The result of Piper betle leaves extract of Ag-Extract NPs showed 32.78 $\mathrm{mm}$ zone of inhibition against $S$. aureus, whereas norfloxacin (positive control) showed maximum $32.15 \mathrm{~mm}$ zone of inhibition for S. aureus (Rashid et al., 2016).

\section{Phytochemical assay}

The crude acetone extract was used for the analysis of phytochemicals by standard method. We tested for eight phytochemical compounds in $A$. indica, however, we found tannin (green precipitate), saponin (foam formation), alkaloids (orange color precipitation followed by buff formation), flavonoid (yellow precipitate) and phenol (dark green color) only (Table 4). These phytochemicals detected, might be a active compounds of plants. On the other hand, Bargah et al., (2015) revealed ethanol and aqueous extracts of Moringa pterygosperma contained various phytochemicals such as alkaloid, flavonoid, glycoside, phenol, saponin, steroid and tannin further, these extract used as antioxidants, antifungal, antibacterial, anti abortifacient. Ethanol extract from Bambusa vulgaris, found terpenoid, flavonoid, carbohydrate, protein, tannin, and glycoside with wound healing and anti inflammatory properties (Lodhi et al., 2016). These results suggested different phytochemicals presence depends on the plant nature and their solvent system used.

\section{TLC analysis}

TLC is used for identification of compounds in a mixture, when the $\mathrm{Rf}$ value of a compound is compared with a known $\mathrm{Rf}$ value compound. From the crude extract of $A$. indica, four major spots were observed with petroleum ether, ethyl acetate (4.2:0.8) with the $\mathrm{Rf}$ value of $0.18,0.36$, $0.70,0.96$. Similarly, Gupta et al., (2013) showed TLC-bioautography suggest that antibacterial compounds may be a polar in nature as several components in the leaf extracts resolved on TLC plates that exhibited clear bactericidal zones. Most of the phytochemicals were found in methanol or ethanol extracts. However, flavanoids was found in all extracts with one spot ( $\mathrm{Rf}$ value 0.8 for acetone, 0.91 for methanol, 0.81 for chloroform and 0.73 for aqueous extract) in Reinwardtia indica plant (Sonam et al., 2017). Thenmozhi and Rajan (2012) also reported four compounds (pale yellow, green yellow, green) were identified in alcohol and aqueous crude extract of $A$. indica.

Antibacterial activity using partially purified compounds of $A$. indica

The two major spots in the TLC plates were scrabbled and checked antimicrobial activity against selected $B$. cereus pathogen. Among 10 pathogens tested for antimicrobial activity with crude extract, $B$. cereus also showed maximum and clear zone of inhibition, hence we selected this organism to check inhibition activity for partially purified compounds. The selected spots show significant activity against $B$. cereus. Of these, two TLC spots, second spot (Rf value 0.70 ) showed good activity compared to first spot (0.96). These partially purified compounds showed significant activity related to tetracycline antibiotics.

\section{CONCLUSION}

In this present study, five solvents were used for $A$. indica plant extract ethanol followed by acetone is suitable for maximum crude extract. However, acetone extract of $A$. indica showed good inhibition activity against human pathogens other than ethanol, diethyl ether, ethyl acetate and benzene extracts. Among ten human pathogens tested for antimicrobial activity, S. typhi followed by $B$. cereus highly inhibited whereas $E$. coli, and S. epidermidis also pronounced well in A. indica extract. For the pharmacological applications this plant extract would be purified as a single 
compound and also identified the bio-active molecule.

\section{ACKNOWLEDGMENTS}

We are thankful to the Department of Chemistry, VHNSN College, Viruthunagar, Immunology and Microbial Technology, SBS, Madurai Kamaraj University, Madurai for providing the facilities and bacterial cultures. NB acknowledge to DST-SERB for Ramanujan Fellowship award No.SB/S2/RJN-201/2014.

\section{CONFLICT OF INTEREST}

All authors declares that there is no conflict of interest.

\section{FUNDING}

None.

\section{AUTHORS' CONTRIBUTION}

VT, contributed the data and drafted the manuscript. NB worked for antimicrobial activity, manuscript interpretation, VS, outline and reviewed the manuscript and CK supervised and reviewed the manuscript for improvisation. VT, NB, VS and CK read and approved the manuscript.

\section{DATA AVAILABILITY}

All datasets generated or analyzed during this study are included in the manuscript.

\section{ETHICS STATEMENT}

Not applicable.

\section{REFERENCES}

1. Alavijeh PK, Alavijeh PK, Sharma D. A study of antimicrobial activity of few medicinal herbs. Asian Journal of Plant Science and Research, 2012; 2(4): 496-502.

2. Apu AS, Liza MS, Jamaluddin ATM, Howlade MA, Saha RK et al. Phytochemical screening and in vitro bioactivities of the extracts of aerial part of Boerhavia diffusa Linn. Asian Pacific Journal of Tropical Biomedicine, 2012; 2(9): 673-678. https:// doi.org/10.1016/S2221-1691(12)60208-1

3. Bargah R. Preliminary test of phyto chemical screening of crude Ethanolic and aqueous extract of Moringa pterygosperma Gaertn. Journal of Pharmacognosy and Phytochemistry, 2015; 4(1): 07-09.

4. Burkill HM. The Useful Plants of West Tropical Africa. Royal Botanic Gardens, Kew, UK, 1985; 2: 246.

5. Devi N, Prabhakaran J, Wahab F. Phyto chemical analysis and enzyme analysis of endophytic fungi from Centella asiatica. Asian Pacific Journal of Tropica Biomedicine, 2012; 2(3): S1280-S1284. https://doi. org/10.1016/S2221-1691(12)60400-6

6. Esakkirajan M, Prabhu NM, Arulvasu C, Beulaja M, Manikandan R, Thiagarajan R, Govindaraju K, Prabhu D, Dinesh D, Babu G, Dhanasekaran G. Anti proliferative effect of a compound isolated from Cassia auriculata against human colon cancer cell line HCT 15. Spectrochimica Acta A Biomolspectrosc, 2014; 120: 462-466. https://doi.org/10.1016/j.saa.2013.09.102

7. Gupta V, Kaur C, Simlai A, Roy A. Antimicrobial activity of Pavetta indica leaves. Journal of Applied Pharmaceutical Science, 2013; 3(4): 078-082.

8. Harborne JB. Phyto chemical Methods, Chapman and Hall Ltd., London, 1973; 49-188.

9. Khurram M, Khan MA, Hameed M, Abbas N, Qayum A. et al. Antibacterial Activities of Dodonaea viscosa using Contact Bioautography Technique. Molecules, 2009; 14: 1332-1341. https://doi.org/10.3390/ molecules14031332

10. Lodhi S, Alok P, Awesh K. Preliminary investigation for wound healing and anti inflammatory effects of Bambusa vulgaris leaves in rats. Journal of Ayurveda and Integrative Medicine, 2016; 7(1): 14-22. https:// doi.org/10.1016/j.jaim.2015.07.001

11. Nostro A, Germano MP, Angelo DV, Marino A, Cannatelli MA. Extraction methods and bioautography for evaluation of medicinal plant antimicrobial activity. Lett Appl Microbiol., 2000; 30(5): 379-84. https://doi. org/10.1046/j.1472-765x.2000.00731.x

12. Rajaselvam J, Benilasmily JM, Meena R. A Study of Antimicrobial Activity of Acalypha indica Against Selected Microbial Species. International Journal of Pharma Sciences and Research, 2012; 3: 473-476.

13. Ramamurthy V, Maria Rajeswari D, Gowri R, Vadivazhagi MK, Jayanthi G, Raveendran S. Study of the Phyto chemical Analysis and Antimicrobial Activity of Dodonaea viscosa. International Journal of Pure and Applied Zoology, 2013; 1(2): 178-184.

14. Rani MS, Pippallai RS, Mohan K. Dodonaea viscosa linn. An Overview. Journal of Pharmaceutical Research and health Care, 2009; 1: 97-112.

15. Rashid M, Shafil Islam M, Azizul Haque M, Tanvir Hossain M, Abdul Hamid M. Anti bacterial activity of poly aniline coated silver nano particles synthesized from piper betle leaves extract. Iranian Journal of Pharmaceutical Research, 2016; 15(2): 591-597.

16. Sathish PVV, Sunita K. Antimalarial efficacy of Pongamia pinnata (L) Pierre against Plasmodium falciparum (3D7 strain) and Plasmodium berghei (ANKA). BMC Complementary and Alternative Medicine, 2017; 458. https://doi.org/10.1186/s12906-017-1958-y

17. Shafeeq SR, Shekshavali T, Sulthan Ahamed SSN. A review on Cassia auriculata. Research Journal of Pharmacology and Pharmacodynamics, 2018; 10(3): 141-145. https://doi.org/10.5958/23215836.2018.00026.5

18. Singh AP. Promising Phytochemicals from Indian Medicinal Plants, Ethnobotanical Leaflets 2005, (1), Article 18.

19. Sofowara A. Phytochemical Screening of Nigerian Medicinal Plants, part III, Lioyeria, 1990; 41: 234-246. 
20. Sofowora A. Research on medicinal plants and traditional medicine in Africa. Journal of Alternative and Complementary Medicine, 1996; 2(3): 365- 372. https://doi.org/10.1089/acm.1996.2.365

21. Sonam M, Singh RP, Pooja S. Phyto chemical Screening and TLC Profiling of Various Extracts of Reinwardtia indica. International Journal of Pharmacognosy and Phyto Chemical Research., 2017; 9(4): 523-527. https://doi.org/10.25258/phyto.v9i4.8125

22. Thenmozhi S, Rajan S. Screening of Antibacterial and Phytochemical activity of Acalypha indica Linn against isolated respiratory pathogens. Research in Plant
Biology, 2012; 2(1): 01-06.

23. Trease GE, Evans WC. Pharmacognosy. $11^{\text {th }}$ edn, Baillere Tindoll, London, 1989; 45-50.

24. Ujwal P, Kumar P, Raja Naika H, Hosettie BB. Antimicrobial activity of different extracts of Pongamia pinnata. Medicinal and aromatic plant science and Biotechnology, 2007; 1(2): 285-287.

25. Wachtel-Galor and Benzieet. Herbal Medicine: Biomolecular and Clinical Aspects. 2nd edition. 2011, Edited by Boca Raton (FL), CRC Press, Taylor and Francis. 